\title{
Comparative study of intrathecal bupivacaine and bupivacaine with midazolam to assess the duration and quality of spinal anesthesia in lower abdominal and lower limb surgeries
}

\author{
Shiva Kumar B S ${ }^{1}$, Ravi Kumar²* \\ ${ }^{1}$ Assistant Professor, Department of Anaesthesia, Sri Siddartha Medical College, Agalakote, Tumkur, Karnataka, INDIA. \\ ${ }^{2}$ Professor, Department of Anaesthesia, DMWIMS, Meppadi, Wayanad, Kerala, INDIA. \\ Email: rknnese@gmail.com, ravinese@yahoo.com
}

Abstract Background: Spinal anesthesia is the anesthesia of choice in lower abdominal and lower limb surgeries. And usage of adjuvants along with Bupivaciaine is extensive. Intrathecal Midazolam to Bupivacaine significantly improved the duration and quality of analgesia in postoperative period in spinal anesthesia without significant side effects. We compared intrathecal Bupivacaine with or without midazolam to assess the duration and quality of post operative analgesia in spinal anesthesia in lower abdominal and lower limb surgeries in the postoperative period. Methods: Sixty patients belonging to ASA I and II, aged 20 to 50 years scheduled for elective lower abdominal and lower limb surgeries were randomized into group B and group BM. Group B received $3.0 \mathrm{ml}$ hyperbaric bupivacaine $0.5 \%$ plus $0.5 \mathrm{ml}$ saline intrathecally $(\mathrm{n}=30)$; group $\mathrm{BM}$ received $3.0 \mathrm{ml}$ bupivacaine plus $0.5 \mathrm{ml}$ midazolam $(5 \mathrm{mg} / \mathrm{ml})$ intrathecally $(\mathrm{n}=30)$. The time of onset of sensory and motor block, hemodynamic status, time for two dermatomal segments regression of sensory level and regression of sensory level, time of first request of analgesics, visual analogue score and adverse effects were compared in both the groups. Results: Mean duration of postoperative analgesia was 126.50 \pm 22.52 minutes in group B compared with $337.24 \pm 33.68$ minutes in group BM $(\mathrm{p}<0.001)$. VAS at first pain medication was 7.93 \pm 0.69 in Group B compared with $6.63 \pm 0.76$ in Group BM. $(p<0.001)$ Number of times analgesic given in twenty four hours was $3.57 \pm 0.5$ in Group B compared to $2.03 \pm 0.49$ in Group BM ( $<<0.001)$. Rescue analgesic dose requirement was significantly less in group BM $(1.20 \pm 0.61)$ compared with group B $(3.03 \pm 0.18)$ $(\mathrm{p}<0.001)$. Time to onset of sensory analgesia at the dorsum of foot, maximum level of sensory block, time to reach it was comparable. Conclusion: An intrathecal dose of $2.5 \mathrm{mg}(0.5 \mathrm{ml})$ of midazolam used with Bupivacaine for spinal anesthesia enhances the onset of action, prolongs the duration of postoperative analgesia with a low demand for opioids in the first 24 hours after surgery with hemodynamic stability, without significant prolongation of motor block and significantly lesser side effects.

Key Words: Intrathecal midazolam, Bupivacaine, postoperative Analgesia.

*Address for Correspondence:

Dr Ravi Kumar, Professor, Department of Anaesthesia, DMWIMS, Meppadi, Wayanad, Kerala, INDIA.

Email: ravinese@yahoo.com

Received Date: 17/04/2020 Revised Date: 23/05/2020 Accepted Date: 11/06/2020

DOI: https://doi.org/10.26611/10151516

This work is licensed under a Creative Commons Attribution-NonCommercial 4.0 International License. (cc)) EY-NC

\begin{tabular}{|l|l|}
\hline \multicolumn{2}{|c|}{ Access this article online } \\
\cline { 1 - 2 } Quick Response Code: & Website: \\
& www.medpulse.in \\
& \\
\hline
\end{tabular}

\section{INTRODUCTION}

Spinal anesthesia has many advantages over general anesthesia which makes it the anesthesia of choice in the present surgical practice. Some clinical studies suggest that postoperative morbidity and possibly mortality may be reduced when a neuraxial blockade is used either alone or in combination with general anesthesia in some settings. It is cost effective both for the patient and for the hospital, as it decreases the stay. Adequate muscle relaxation is obtained following spinal and blood loss is reduced which makes it superior to general anesthesia. It may also allow earlier return of gastrointestinal function following surgery. Following spinal anesthesia there is reduction of the hypercoagulable state associated 
with surgery, sympathectomy mediated increases in tissue blood flow, improved oxygenation from decreased splinting, enhanced peristalsis and suppression of the neuroendocrine stress response to surgery. ${ }^{1}$ Spinal anesthesia is also unable to maintain postoperative analgesia for a longer period with commonly used drugs which has been identified as deficiencies in pain management today. Despite the availability of effective analgesic agents, patients continue to suffer severe postoperative pain. With the conventional practice of supplementing with analgesics, in the postoperative period, the analgesia many patients receive is simply too little or too late. Various adjuvants have been added to intrathecal bupivacaine like Morphine, ${ }^{2}$ Clonidine and Neostigmine to prolong the duration of spinal anesthesia with side effects. In light of these existing problems we need to opt for a practice that provides a better pain management which is essential for early recovery of motor function and reduced requirement of post-operative analgesics. Intrathecal Midazolam however has shown promising results to address the current problem. In various studies, results suggesting that addition of Midazolam to Bupivacaine intrathecally provided better postoperative analgesia without any adverse effects with lesser requirements of rescue analgesics. Hence this study is designed to study the efficacy of combination of intrathecal midazolam and bupivaciane for duration, quality of spinal anesthesia and postoperative analgesia.

\section{METHODOLOGY}

Institutional Review Board approval and written informed consent obtained from the patient, 60 patients both male and female,(ASA I and II) aged 20 to 50 years scheduled for elective surgeries, meeting the inclusion criteria and not having any of the exclusion criteria were taken for the study.

Inclusion Criteria:

1. Patients of either sex.

2. Patients with ASA Grade-I and Grade-II

3. Patients aged between 18-60 years.

Exclusion criteria:

1. Patient refusal

2. Local infection at the puncture site

3. Coagulopathy

4. Intracranial hypertension

5. Progressive degenerative neurological disease

6. Low back pain

7. Allergy to the study drugs

8. Failure of procedure

Patients were selected randomly by lottery method where group ' $\mathrm{B}$ ' received intrathecal hyperbaric bupivacaine $0.5 \% 3.0 \mathrm{ml}$ only and group 'BM' received intrathecal hyperbaric bupivacaine $3.0 \mathrm{ml}$ with preservative free midazolam $2.5 \mathrm{mg}$. A day before surgery pre operative evaluation of patients was done, with relevant laboratory investigations and keeping patient nil per orally from midnight. Visual analogue scale (VAS-consisting of $100 \mathrm{~mm}$ line with $0=$ no pain and $100=$ worst possible pain) was explained to all patients during the preoperative visit with written informed consent. Inside the operation theatre, monitoring was established with electrocardiography, pulse oximetry and non-invasive blood pressure measuring device. Intravenous line was opened with a 16 Gauze cannula and a preload of $10 \mathrm{ml} / \mathrm{kg}$ of Ringer's lactate solution was administered. Under all aseptic precautions cleaning and draping was done. Subarachnoid block was performed at the lumbar 3-4 inter space in the sitting position using a $25 \mathrm{G}$ spinal needle, Quincke type. Once free flow of clear cerebrospinal fluid was demonstrated the study drugs were administered intrathecally and the patients were immediately placed in the supine position. Time of onset of sensory analgesia at the dorsum of foot, (loss of sharp sensation to pinprick with a small blunted needle), maximum level of sensory block and the time required to achieve it were noted. The observations were assessed at two minutes intervals for fifteen minutes after intrathecal injection. The degree of motor block was recorded before incision and after completion of surgery using the Modified Bromage Scoring. Heart rate, blood pressure, oxygen saturation and level of sedation (using the sedation score described by Chernik et al., were recorded at 2 minute interval for 15 minutes and every 10 minutes throughout the surgery. Intraoperative hypotension (a 20-30\% decrease in SBP from the baseline value) was treated with IV fluid and Mephentermine in the $3 \mathrm{mg}$ increment dose. Hemodynamic changes and the level of sedation was assessed(using the sedation score by Chernik et al.,) every hour for six hours postoperatively. Postoperatively, in addition to the above, Visual Analogue Scale score for pain was noted at 4, 6, 12 and 24 hours. The patients were asked to answer verbally and by pointing to where they would rate their pain using the numerical scale. Rescue analgesics were administered when VAS score was four. Seventy five $\mathrm{mg}$ of diclofenac sodium intramuscularly was given and if satisfactory analgesia was not achieved, Pethidine $1 \mathrm{mg} \cdot \mathrm{kg}^{-1}$ and Promethazine $25 \mathrm{mg}$ was administered intramuscularly. Time to first analgesic (time between intrathecal injection and first administration of additional analgesic), and the total number and doses of analgesics and antiemetic required in the first twenty four hours postoperatively were recorded. Time to first micturition and side effects like (nausea and vomiting, itching, urinary retention and sedation) were recorded. Adverse effects (if any) were treated with the respective drugs. For nausea and or vomiting ondansetron $4 \mathrm{mg}$ IV was given. Patients were encouraged to void urine. For urinary retention catheterization was done. 
Analysis of data

Collected data were analyzed by means of various statistical software such as SPSS and appropriate tests. Priority was given to the numeric scores obtained from duration of effective analgesic time, degree of motor block and changes in heart rate and blood pressure. To adjust for differences between the groups due to other factors which were considered responsible for the outcomes were also evaluated separately in multiple regression analysis. In order to simplify the interpretation of analysis some continuous data were collapsed into dichotomized data indicating a positive response versus non response. Overall significance level was maintained at $\mathrm{p}<0.05$.

Ethical Committee approval was taken from Institution.

\section{RESULTS}

A total of 60 patients were taken for the study. In group B, the mean age of patient was $34.13 \pm 9.8$ years, mean weight was $56.13 \pm 6.6 \mathrm{~kg}$ and mean height was $164.13 \pm 5.1 \mathrm{~cm}$. Male patients were $63.3 \%$ and female patients were $36.7 \%$. In group BM, the mean age of the patient was $30.97 \pm 9.1$ years, mean weight $55.07 \pm 7.5 \mathrm{~kg}$ and mean height was $163.13 \pm 4.5 \mathrm{~cm}$. Duration of surgery in Group B was $63.9 \pm 26.78$ minutes and in Group BM was $58.23 \pm 24.47 \mathrm{~min}$. Data shown in Table 1 and 2.

\begin{tabular}{cccc}
\multicolumn{4}{c}{ Table 1: Demographic data of the patients } \\
\hline & Group B & Group BM & p value \\
\hline Age( in years) & $34.13 \pm 9.8$ & $30.97 \pm 9.1$ & 0.20 \\
Weight (in kg) & $56.13 \pm 6.6$ & $55.07 \pm 7.5$ & 0.56 \\
Height (in cm) & $164.13 \pm 5.1$ & $163.13 \pm 4.5$ & 0.43 \\
Duration of surgery(min) & $63.9 \pm 26.78$ & $58.23 \pm 24.47$ & 0.39 \\
\hline
\end{tabular}

The commonest operative procedure was interval appendicectomy followed by mesh repair and ORIF with IMIL. Onset of analgesia between the two groups are shown figure 1. In group B onset of analgesia was less than 5 minutes in 23 patients and in 5-10 minutes in the remaining patients. In group BM onset of analgesia was less than 5 min in all the patients and the difference between the two groups was significant.

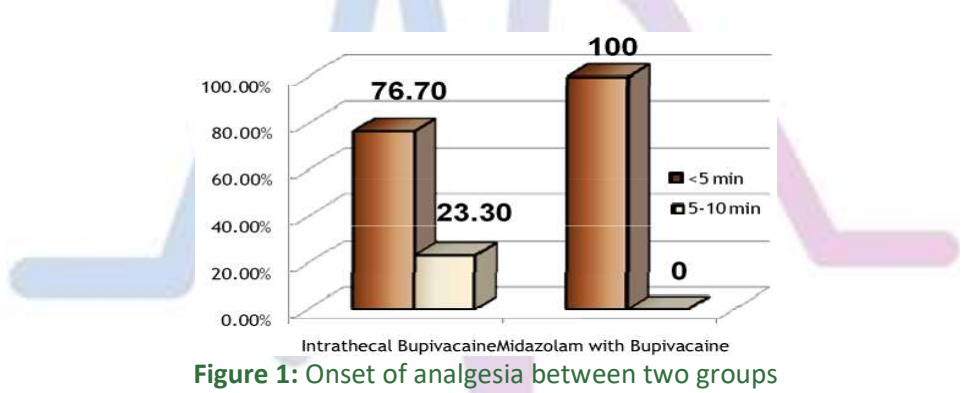

Time to achieve maximum sensory level was $8.6 \pm 1.1$ minutes in group BM compared to group B where it was $9.63 \pm 1.4$ min P value was 0.003 and statistically significant.

Table 2: Onset of maximum analgesia between both groups:

\begin{tabular}{ccccc}
\hline & & Group B & Group BM & p value \\
\hline Maximum sensory level & T6 & $15(50 \%)$ & $14(46.7 \%)$ & \\
& T7 & $9(30 \%)$ & $11(36.7 \%)$ & \\
& T8 & $6(20 \%)$ & $5(16.7 \%)$ & \\
Time to achieve maximum sensory level $(\mathrm{min})$ & & $9.63 \pm 1.4$ & $8.6 \pm 1.1$ & $\mathbf{0 . 0 0 3}$ \\
\hline
\end{tabular}

Values are in number and percent along with mean \pm SD

Levels of sensory block was from T8-T6. The result shows no significant differences between the groups. Heart rate, systolic blood pressure, diastolic blood pressure, mean arterial pressures during intraoperative period there was not any significant differences in these parameters between both groups. The patients were monitored for the first six hours after surgery, to assess any abnormalities in heart rate, blood pressure and saturation. All the patients in both groups were haemodynamically stable. Time to first pain medication was significantly longer in group BM, $337 \pm 33.6$ minutes compared to Group B $126.50 \pm 22.52$ minutes $(p<0.001)$.VAS at first pain medication was shorter in Group BM $(\mathrm{p}<0.005)$ Number of times analgesics given in group B were $3.57 \pm 0.5$, whereas in group BM 2.03 \pm 0.4 . $p<0.001$, and statistically significant. Patients in group B required significantly greater number of rescue analgesics (3.03 \pm 0.18$)$ compared with group BM $(1.2 \pm 0.6) \mathrm{p}<0.001$ and statistically significant. Number of times antiemetic given was also lesser in group BM and was comparable. p value was 0.01 . 
Table 3: Duration of Analgesia

\begin{tabular}{cccc}
\hline & Group B & Group BM & P value \\
\hline Time to 1st pain medication(hr) & $126.50 \pm 22.52$ & $337.24 \pm 33.68$ & $<\mathbf{0 . 0 0 1}$ \\
VAS at 1st pain medication & $7.93 \pm 0.69$ & $6.63 \pm 0.76$ & $<\mathbf{0 . 0 0 1}$ \\
No of times analgesics given & $3.57 \pm 0.50$ & $2.03 \pm 0.49$ & $<0.001$ \\
No- of times rescue analgesics given & $3.03 \pm 0.18$ & $1.20 \pm 0.61$ & $<0.001$ \\
No. of times antiemetic given & $0.33 \pm 0.6$ & $0.03 \pm 0.18$ & $\mathbf{0 . 0 1}$ \\
\hline \multicolumn{2}{c}{ Values are in mean \pm SD }
\end{tabular}

In Postoperative period, Visual Analogue scoring (for pain) were recorded for first 24 hours after surgery. VAS was $<$ 0.001 in 4, 12 and 24 hours and was statistically significant.

Table 4: Postoperative Visual Analogue scores for pain at various point times

\begin{tabular}{cccc}
\hline VAS scores & Group B & Group BM & p value \\
\hline VAS at 4 hours & $7.80 \pm 0.8$ & $4.43 \pm 0.5$ & $<0.001$ \\
VAS at 6 hours & $6.43 \pm 0.6$ & $6.20 \pm 0.6$ & 0.16 \\
VAS at 12 hours & $6.20 \pm 0.6$ & $5.50 \pm 0.7$ & $<0.001$ \\
VAS at 24 hours & $4.40 \pm 0.6$ & $3.53 \pm 0.5$ & $<0.001$ \\
\hline \multicolumn{4}{c}{ Values are in mean \pm SD }
\end{tabular}

Motor block before and after surgery was assessed using the Modified Bromage scoring ( MBS, Annex-I). In group B $13.3 \%$ had MBS of 2 and $86.7 \%$ had MBS of 3 before surgery. In group BM $3.3 \%$ had MBS of $1,10 \%$ had MBS of 2 and $86.7 \%$ had MBS of 3 before surgery. After surgery $15 \%$ of patients in group B had MBS of 2 and $85 \%$ MBS of 3 and in group BM 6.7\% had MBS of 2 and $93.3 \%$ had MBS of 3. Data shown in figure 2.

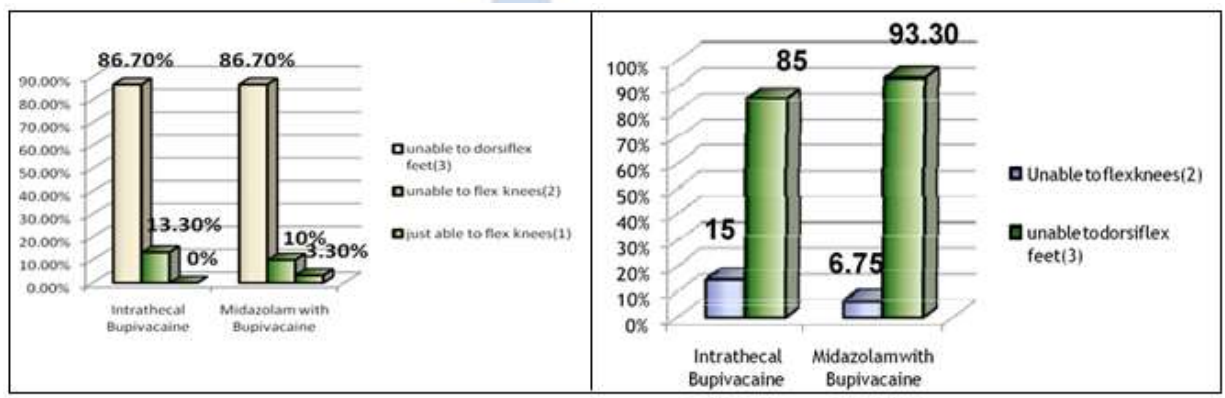

Figure 2: Bromage score between the two groups before surgery

Figure 3: Motor block after surgery

In the postoperative period side effects were assessed for the first twenty four hours after surgery. Three patients in group B had nausea and vomiting in the fourth hour, 3 in the $6^{\text {th }}$ hour and 2 patients had in the 12 th hour whereas only one patient in group BM had nausea in the $4^{\text {th }}$ hour. They were treated with Inj Ondansetron $4 \mathrm{mg}$ IV. One patient in Group B had itching in the $4^{\text {th }}$ hour but did not needed any active intervention. All patients in group B had urinary retention till the $4^{\text {th }}$ hour, 19 patients had till the $6^{\text {th }}$ hour. 9 patients in group BM had urinary retention till the $4^{\text {th }}$ hour.

\begin{tabular}{|c|c|c|c|c|c|c|c|c|}
\hline & \multicolumn{2}{|c|}{$4 \mathrm{hr}$} & \multicolumn{2}{|c|}{$6 \mathrm{hr}$} & \multicolumn{2}{|c|}{$12 \mathrm{hr}$} & \multicolumn{2}{|c|}{$24 \mathrm{hr}$} \\
\hline & B & BM & B & BM & B & BM & B & BM \\
\hline Nausea and vomiting & $10 \%(3)$ & $3.4 \%(1)$ & $10 \%(3)$ & - & $6.7 \%(2)$ & $3.3 \%(1)$ & - & - \\
\hline Itching & $3.4 \%(1)$ & - & - & - & - & - & - & - \\
\hline Urinary retention & $\begin{array}{c}100 \%(3 \\
0)\end{array}$ & $31 \%(9)$ & $\begin{array}{c}63.3 \% \\
(19)\end{array}$ & - & - & - & - & - \\
\hline
\end{tabular}

Intraoperatively, sedation scores were 0 in eighteen patients in group B and 4 patients in group BM. Twelve patients in group B and twenty four patients in group BM had a sedation score of 1. Two patients in group BM had a sedation score (Appendix -2) of 2 (ie the patients were in deep sleep but arousable)

\begin{tabular}{ccc} 
Table 6: Intraoperative sedation scores between the two groups: \\
& Group B & Group BM \\
\hline Sedation scores & 18 & 4 \\
0- Wide awake & 12 & 24 \\
1-sleeping comfortably & 0 & 2 \\
2-Deep sleep, arousable & 0 & 0 \\
3-Deep sleep, unarousable & 0 & \\
\hline
\end{tabular}


In the first six hours after surgery the sedation score was 0 in twenty six patients in Group B and six patients in Group BM. Four patients in Group B and 22 patients in Group BM had a sedation score of 1 . Two patients in Group BM had a sedation score of two for two hours postoperatively.

Table 7: Sedation scores between the two groups in the first six hours after surgery

\begin{tabular}{ccc}
\hline Sedation scores & Group B & Group BM \\
\hline 0- Wide awake & 26 & 6 \\
1-sleeping comfortably & 4 & 22 \\
2-Deep sleep, arousable & 0 & 2 \\
3-Deep sleep, unarousable & 0 & 0 \\
\hline
\end{tabular}

\section{DISCUSSION}

Spinal anesthesia, the choice for lower abdominal and lower limb surgeries, is simple, reliable and popular anesthetic technique. However, it is not devoid of complications. Conventional spinal anesthesia has complications like hypotension, bradycardia, urinary retention, postdural puncture headache, transient or permanent neurological symptoms. Many of these complications specially hemodynamic effects are related with the sympatholytic effect of the local anesthetic agent, others are related with the technique of use (PDPH, neurologic injury, intravascular injection). Another pitfall of spinal anesthesia is that it does not provide postoperative analgesia for a longer time with the commonly used drugs. ${ }^{3}$ Severe postoperative pain is known to adversely affect patient outcome after a variety of surgical procedures. ${ }^{4,5}$ Excessive analgesic drug administration may cause a high incidence of adverse effects in the postoperative period. ${ }^{6}$ Higher the level of block more will be the sympatholytic effect and thus more serious the complications will be. These effects can be considerably minimized, if not abolished, by using the low dose anesthetic agent at lower concentration or possibly by adding another drug as an adjunct. This study was carried out to evaluate the efficacy, duration of action and adverse effects, if any, of $2.5 \mathrm{mg}$ midazolam when given with $0.5 \%$ bupivacaine by intrathecal route for postoperative analgesia in patients undergoing elective lower abdominal and lower limb surgeries. In this study, time of onset of sensory block was less than five minutes in the BM group, compared to five to ten minutes in the $\mathrm{B}$ group and maximum sensory level was T6 to T8 in both groups by which we can predict that midazolam enchases the onset of sensory block when added to Bupivacaine intrathecally. In this study the time to achieve maximum sensory level was $8.6 \pm 1.1 \mathrm{~min}$ in group BM compared to group B where it was $9.63 \pm 1.4$. This was similar to a study done by Sajedi $\mathrm{P}$ et al. where $5 \mathrm{mg}$ midazolam administered epidurally had faster onset of sensory block and shorter time was required for peak effect ${ }^{7}$. Unlike this study, in the study done by Aikta Gupta et al., onset of analgesia was similar between the two groups and maximum level of block and time taken for maximum cephalic spread were not affected after addition of midazolam to bupivacaine as compared with bupivacaine alone ${ }^{8}$. The baseline vitals were noted before spinal anesthesia. The heart rate, blood pressure and saturation were recorded every two minutes for fifteen minutes and then every ten minutes throughout the surgery. In addition, these parameters were recorded every hour for the first six hours postoperatively to exclude any side effects of midazolam. There were not any significant changes in heart rate,blood pressure, saturation in both groups during the intraoperative and postoperative period. This is similar to other studies where all these parameters were within normal limits during the intraoperative and postoperative period. The addition of midazolam 2.5 $\mathrm{mg}$ intrathecally prolonged the duration of spinal analgesia to $337.24 \pm 33.8$ minutes in this study. It is similar to Aikta Gupta et al. where $2.5 \mathrm{mg}$ midazolam intrathecally prolonged the duration of post operative analgesia by $412 \pm 57 \mathrm{~min}^{8}$. The longer duration of analgesia in their study compared to this study might be due to the larger dose of Bupivacaine $(3.5 \mathrm{ml})$ they used in their study. Kim and Lee evaluated the postoperative analgesic effects of intrathecal midazolam with bupivacaine following hemorrhoidectomy where the addition of 1 or $2 \mathrm{mg}$ of intrathecal midazolam prolonged the postoperative analgesic effect of bupivacaine by $2 \mathrm{hr}$ and 4.5 hour, respectively, compared with controls ${ }^{9}$. In addition, midazolam treated groups used less analgesics in the first twenty four hours after surgery. Their results suggested a dosedependent effect of intrathecal midazolam. Prakash et al. used $1 \mathrm{mg}$ and $2 \mathrm{mg}$ midazolam intrathecally with 2 $\mathrm{ml} 0.5 \%$ Bupivacaine in patients undergoing caesarean section under spinal anesthesia. The mean duration of postoperative analgesia was $4.3 \pm 0.7$ hours in group $\mathrm{BM} 1$, and $6.1 \pm 1.0$ hours in group $\mathrm{BM} 2^{10}$. In their results also Bupivacaine with midazolam showed better analgesia than bupivacaine alone at $1 \mathrm{hr}$. They concluded that Intrathecal midazolam appeared safe and had clinically detectable analgesic properties. Shah FR et al. in their study found out that intrathecal midazolam $2 \mathrm{mg}$ improved the quality and duration of postoperative pain relief afforded by intrathecal buprenorphine and bupivacaine ${ }^{11}$. Batra et al. reported an increased duration of postoperative analgesia with intrathecal midazolam $2 \mathrm{mg}$ and bupivacaine in thirty patients undergoing knee arthroscopy ${ }^{12}$. All patients received rescue analgesia in the control group at a mean duration of $258 \pm 46.8$ min whereas only one patient in midazolam- bupivacaine group required supplemental analgesia within this period. In this study VAS score for pain was $7.93 \pm 0.69$ in group B compared to $6.63 \pm 0.76$ in group BM. This was similar to the study done by Aikta Gupta et al. where the VAS pain score was 
shorter in Group BM compared to group B. In the study done by Yegin et al. the postoperative VAS for pain were significantly lower at the first 4 hours in the midazolam group and first analgesic requirement time was significantly longer than the Bupivacaine group ${ }^{13}$. In our study lesser number of analgesics were given in group BM compared to group B. $(p<0.001)$ The number of times rescue analgesics given were also less in group BM compared to group B $(\mathrm{p}<0.001)$ The earliest request for rescue analgesic was at $30 \mathrm{~min}$ in group $\mathrm{B}$ and the late one was 12 hours in group BM. Two patients in group BM did not require analgesics at all in the whole twenty four hours postoperatively. Aikta Gupta et al., Prakash S et al., also found that supplemental analgesic dose requirement with diclofenac was significantly less in group BM compared to Group $\mathrm{B}^{8,10}$. Many studies have evaluated the effects of intrathecal midazolam with bupivacaine for prolonging the duration of postoperative analgesia. Intrathecal midazolam has been found to be an effective treatment for chronic mechanical low back pain in a controlled comparison with epidural steroid in a pilot study done by Serrao Jt et al.. ${ }^{14}$ The analgesic efficacy of epidural and caudal midazolam in combination with local anesthetics has been assessed for postoperative pain relief in adults in a study done by Nishiyama $\mathrm{T}$ et $a l .{ }^{15}$.They found out that midazolam could enhance the analgesic effects of bupivacaine synergistically in intrathecal administration. The side effects were decreased in the combination of the drugs compared with each drug alone. In this study the degree of motor block was assessed using the modified bromage scoring( MBS Annex -I) In group B most of the patients had Bromage score of 3 before surgery and after surgery $15 \%$ had Bromage score of 2 and $85 \%$ had a Bromage score of 3 . In group BM 3.3\% had Bromage score of $1,10 \%$ had 2 and $86.7 \%$ had Bromage score of 3 before surgery. After surgery 6.7\% had Bromage score of 2 and rest had 3 in the BM group. Bharti $\mathrm{N}$ et al. had found that motor block was prolonged in the midazolam group as compared with Bupivacaine alone using the combined spinal epidural technique. ${ }^{16}$ In this study there was decrease incidence of nausea and vomiting in group BM compared to Group B. Prakash et al. had also found that intrathecal midazolam, $1 \mathrm{mg}$ and $2 \mathrm{mg}$, decreased postoperative nausea and vomiting in patients undergoing elective cesarean delivery under spinal anesthesia which shows that intrathecal midazolam can be used for elective cesarean section also with decreased incidence of side effects. ${ }^{10}$

In this study only two patients had a sedation score of 2 (in deep sleep but arousable) Those patients were monitored for respiratory depression until they were awake, which was around two more hours postoperatively. Previous studies done by Serrao Jt have similarly not observed sedation in patients following administration of intrathecal midazolam. ${ }^{17}$
Urinary retention was seen only in the first four hours in the midazolam group compared to the bupivacaine alone group where the retention was for six to twelve hours in all patients. Itching was not found in any patients similar to other studies. A serious risk of intrathecal administration of any drug is its neurotoxicity. In a cohort study investigating safety in 1100 patients, administration of intrathecal midazolam $2 \mathrm{mg}$ did not increase the occurrence of neurologic symptoms ${ }^{18}$. In our study also no signs of neurotoxicity were seen in any patients. In conclusion we can say that, an intrathecal dose of $2.5 \mathrm{mg}(0.5 \mathrm{ml})$ of midazolam used with Bupivacaine for spinal anesthesia enhances the onset of action, prolongs the duration of postoperative analgesia with a low demand for opioids in the first 24 hours after surgery with hemodynamic stability, without significant prolongation of motor block and significantly lesser side effects.

\section{CONCLUSION}

An intrathecal dose of $2.5 \mathrm{mg}(0.5 \mathrm{ml})$ of midazolam used with Bupivacaine for spinal anesthesia enhances the onset of action, prolongs the duration of postoperative analgesia with a low demand for opioids in the first 24 hours after surgery with hemodynamic stability, without significant prolongation of motor block and significantly lesser side effects.

\section{REFERENCES}

1. G.Edward Morgan, Jr .Maged S.Mikhail, Michael J.Murray. Clinical Anaesthesiology;2006, Fourth edition

2. Cousins MJ and Mathes LE. Intrathecal and epidural opioids. Anesthesiology, 1984; 61 (3): 275- 310.

3. Jamison RN, Ross MJ, Hoopman P, Griffin F, Levy J, Daly M, Schafer JL. Assessment of postoperative pain management: patient satisfaction and perceived helpfulness. Clinical Journal of Pain 1997; 13: 229-236

4. Ready L. Postoperative pain management--beyond basics. Canadian Journal of Anaesthesia.1996; 43: 193194.

5. Liebeskind JC Pain can kill. Pain 1991; 44: 3-4.

6. Janig WF, Liebeskind JC. A call for nation initiatives on pain. Pain 1994; 59: 5-6.

7. Sajedi P, Islami M. Supplementing epidural lidocaine with midazolam: effect on sensory motor block level. Acta Anaesthesiology Taiwan. 2004 Sep;42(3):153-7.

8. Aikta Gupta, Smita Prakash, Savita Deshpande, The effect of intrathecal midazolam $2.5 \mathrm{mg}$ with hyperbaric bupivacaine for postoperative pain relief in patients undergoing orthopedic surgery The Internet Journal of Anesthesiology. 2007. Volume 14 Number 2.

9. Kim MH, Lee YM. Intrathecal midazolam increases the analgesic effects of spinal blockade with bupivacaine in patients undergoing haemorrhoidectomy. Br J Anaesth, 2001; 86 (1): 77-79.

10. Prakash S, Joshi N, Gogia AR, Prakash S, Singh R. Analgesic efficacy of two doses of intrathecal midazolam with bupivacaine in patients undergoing cesarean delivery. Reg Anesth Pain Med. 2006 MayJun;31(3):221-6. 
11. Shah FR, Halbe AR, Panchal ID, Goodchild CS. Improvement in postoperative pain relief by the addition of midazolam to an intrathecal injection of buprenorphine and bupivacaine. Eur J Anaesthesiology 2003; 20: 904-910.

12. Batra YK, Jain K, Chari P et al.. Addition of intrathecal midazolam to bupivacaine produces better post operative analgesia without prolonging recovery. International Journal of Clinical Pharmacology Ther 1999; 37 (10): 519-527.

13. Yegin A, Sanli S, Dosemeci L, Kayacan N, Akbas M, Karsli B,Akdeniz intrathecal midazolam combined with intrathecal bupivacaine produces a more effective and longer analgesia with a mild sedative effect in perianal surgery Eur J Anaesthesiology 2004 Aug: 21(8):658-62

14. Serrao Jt, Marks RL, Morley SJ, Goodchild CS. Intrathecal midazolam for the treatment of chronic mechanical low back pain: a controlled comparison with epidural steroid in a pilot study. Pain, 1992; 48: 5-12.

15. Nishiyama T, Yokoyama AT, Odaka Y, Kanishi H, Gotol SG. Midazolam improves postoperative epidural analgesia with continuous infusion of local anaesthetics. Can J Anaesth, 1998; 46: 551-555

16. Bharti N, Madan R, Mohanty PR, Kaul HL Addition of intrathecal midazolam to intrathecal bupivacaine on duration and quality of spinal blockade. Acta Anaesthesiology Scand. 2003 Oct;47(9):1101-5

17. Serrao Jt, Marks RL, Morley SJ, Goodchild CS. Intrathecal midazolam for the treatment of chronic mechanical low back pain: a controlled comparison with epidural steroid in a pilot study. Pain, 1992; 48: 5-12.

18. Tucker et al. , Intrathecal Midazolam I: A Cohort Study Investigating Safety Anesthesia and Analgesia: June 2004 - Volume 98 - Issue 6 - p 1512-1520.

\section{Source of Support: None Declared \\ Conflict of Interest: None Declared}

Policy for Articles with Open Access:

Authors who publish with MedPulse International Journal of Anesthesiology (Print ISSN:2579-0900) (Online ISSN: 2636-4654) agree to the following terms: Authors retain copyright and grant the journal right of first publication with the work simultaneously licensed under a Creative Commons Attribution License that allows others to share the work with an acknowledgement of the work's authorship and initial publication in this journal.

Authors are permitted and encouraged to post links to their work online (e.g., in institutional repositories or on their website) prior to and during the submission process, as it can lead to productive exchanges, as well as earlier and greater citation of published work. 